\title{
BMJ Open Composition of objectively measured physical activity and sedentary behaviour participation across the school-day, influence of gender and weight status: cross-sectional analyses among disadvantaged Victorian school children
}

\author{
Claudia Strugnell, ${ }^{1}$ Kyle Turner, ${ }^{2}$ Mary Malakellis, ${ }^{1}$ Josh Hayward, ${ }^{1}$ Charlie Foster, ${ }^{2}$ \\ Lynne Millar, ${ }^{1,3}$ Steve Allender ${ }^{1,3}$
}

To cite: Strugnell C,

Turner K, Malakellis M, et al. Composition of objectively measured physical activity and sedentary behaviour participation across the school-day, influence of gender and weight status: cross-sectional analyses among disadvantaged Victorian school children. BMJ Open 2016;6:e011478. doi:10.1136/bmjopen-2016011478

- Prepublication history and additional material is available. To view please visit the journal (http://dx.doi.org/ 10.1136/bmjopen-2016011478)

Received 2 March 2016 Revised 24 June 2016 Accepted 9 August 2016

CrossMark

For numbered affiliations see end of article.

Correspondence to Dr Claudia Strugnell; claudia.strugnell@deakin.edu.au

\section{ABSTRACT}

Background: The after-school period has been described as the 'critical window' for physical activity (PA) participation. However, little is known about the importance of this window compared with the before and during-school period among socioeconomically disadvantaged children, and influence of gender and weight status.

Methods: 39 out of 156 (RR=25\%) invited primary schools across 26 local government areas in Victoria, Australia, consented to participate with 856 children (RR $=36 \%$ ) participating in the wider study. The analysis sample included 298 Grade 4 and Grade 6 children (mean age: $11.2 \pm 1.1 ; 44 \%$ male) whom met minimum accelerometry wear-time criteria and had complete height, weight and health-behaviours questionnaire data. Accelerometry measured duration in daily light-intensity PA (LPA), moderate-to-vigorous PA (MVPA) and sedentary time (ST) was calculated for before-school=8-8:59, during-school=9:00-15:29 and after-school=15:30-18:00. Bivariate and multivariable linear regression analyses were conducted.

Results: During-school represented the greatest accumulation of LPA and MVPA compared with the before and after-school periods. Boys engaged in $102 \mathrm{~min} /$ day of LPA ( $95 \% \mathrm{Cl} 98.5$ to 104.9$)$ and $62 \mathrm{~min} /$ day of MVPA ( $95 \% \mathrm{Cl} 58.9$ to 64.7 ) duringschool; girls engaged in $103 \mathrm{~min} /$ day of LPA $(95 \%$ $\mathrm{Cl} 99.7$ to 106.5$)$ and $45 \mathrm{~min} /$ day of MVPA $(95 \% \mathrm{Cl}$ 42.9 to 47.4 ). Linear regression models indicated that girls with overweight or obesity engaged in significantly less LPA, MVPA and more time in ST during-school.

Conclusions: This study highlights the importance of in-school PA compared with after-school PA among socioeconomically disadvantage children whom may have fewer resources to participate in after-school PA.

\section{Strengths and limitations of this study}

- This study has various strengths that centre on the objective examination of the physical activity and sedentary behaviour across the school-day with measured anthropometric indices among disadvantaged primary school children.

- Additionally, this study examines the importance of the before-school, during-school and afterschool period for physical activity and sedentary behaviour participation which are commonly examined in isolation, with many studies focusing on the after-school period.

- A limitation of this study is the cross-sectional nature of the data that arises from a subsample of possible participants due to the limited number of accelerometers available to the study team.

- Another limitation is the sampling strategy used which deliberately focused on local government areas with high rates of chronic disease and levels of socioeconomic disadvantage, and thus are not representative of the Victorian population.

\section{INTRODUCTION}

Regular physical activity (PA) participation has many documented health benefits for children and adolescents. ${ }^{1}{ }^{2}$ Low levels of PA (termed physical inactivity) among youths have been associated with negative outcomes, including lower high-density lipoprotein cholesterol, hypertension, metabolic syndrome and obesity ${ }^{1}$ and increased mental health outcomes (depression, anxiety, self-esteem and cognitive function). ${ }^{3}$ Representative self-report 
data indicate that approximately $80.4 \%$ of Australian children and adolescents (aged 5-17 years) ${ }^{4}$ engaged in insufficient levels of moderate-to-vigorous physical activity (MVPA) to confer the health benefits $(\geq 60 \mathrm{~min} /$ day of MVPA every day). ${ }^{5}$ Together with high levels of sedentary behaviours (SB), ${ }^{4}$ which are also linked to negative health ${ }^{6}$ physical inactivity remains a pressing public health concern.

A variety of individual, environmental and psychosocial influences have been associated with PA and SB participation. ${ }^{78}$ Parallels exist with obesity which is also now accepted to result from a complex array of influences. ${ }^{9}$ Single interventions have provided modest changes in child and adolescent $\mathrm{PA}^{10}{ }^{11}$ and $\mathrm{SB},{ }^{12} 13$ leading to a shift in focus to multicomponent interventions. ${ }^{10}{ }^{11}$ Schools have become a key setting for single and multiple intervention approaches targeting increasing PA and reduction in SB. The focus on schools is logical due to the sheer volume of time children spend in school and the strong structures (eg, policy, governance, curriculum and fiscal) that influence these environments and are relatively easy to manipulate to try and change PA and SB behaviours. Improvements in PA and nutrition within the school will also help address inequities, as they offer an unsurpassed opportunity to reach all children. ${ }^{14}$ Health equity has been defined as 'the absence of potentially remediable, systematic difference in one or more aspects of health across socially, economically, demographically, or geographically defined population groups or subgroup' ${ }^{15}$ Although, it is acknowledged that schools cannot singularly reverse physical inactivity and SB, but offer great potential in ensuring students achieve the recommended amount MVPA. ${ }^{10} 14$

Efforts to understand the effectiveness of interventions and participation behaviours in schools are hampered by a lack of objective measurement of PA and sedentary behaviour time (ST) across the whole school day. ${ }^{16}$ This is emphasised by the limited international literature. Variations in school times and durations appear to be strong determinants of MVPA and ST among school-aged children. ${ }^{17}$ A five country European study (Belgium, Greece, Hungary, the Netherlands, Switzerland) among 1025 children (aged 10-12 years) with valid accelerometry found students spent $4-6 \%(\sim 13-21 \mathrm{~min} /$ day $)$ of the school-day in MVPA and 61-70\% ( 182-231 min/day) in ST. ${ }^{17}$ In addition, a Canadian study among 380 children (aged 8-11 years) found that $14 \%$ of and $71 \%$ of the school-day was spent in MVPA and ST, respectively, for girls ( $53 \mathrm{~min} /$ day MVPA and $260 \mathrm{~min} /$ day ST) and $17 \%$ and $67 \%$ for boys ( $64 \mathrm{~min} /$ day MVPA and $246 \mathrm{~min} /$ day ST).${ }^{18}$ To date, it is believed that there is no objective measurement of PA and ST participation across the entire school day (before, during, after-school) and associations with weight status within the Australian primary school context.

This paper reports on the segmented patterns of PA and ST among Grade 4 and Grade 6 Australian primary school children with valid accelerometry data during September-December 2013 (Term 4). The paper sets out to answer the following questions:

1. What is the composition of PA and ST before-school, during-school and after-school among predominantly socioeconomically disadvantaged primary school children?

2. What influence does weight status have on the composition of PA and ST across the school-day and does this vary by gender?

It is hypothesised that the during-school period will represent the greatest accumulation of PA among the current sample and that children with overweight or obesity will engage in significantly less PA and ST before, during and after-school than their peers with healthy weight.

\section{METHODS}

\section{Setting, study population and sampling}

This cross-sectional pilot data derive from the Healthy Together Victoria (HTV) and Childhood Obesity study which aims to measure the impacts of HTV on anthropometric and obesogenic behaviours among Victorian children and the environments in which they live. Embedded within HTV is a cluster-randomised control trial of 12 prevention and 11 comparison clusters which were selected through their matched randomisation based on their demographic (Socioeconomic Index for Areas (SEIFA) $)^{19}$ and chronic disease risk factor prevalence (ie, unhealthy weight) of adults within participating local government areas (LGAs). This study involved the collection of anthropometric and behavioural data among primary and secondary school children from 26 LGAs; the details of which have previously been published..$^{20}$ In brief, a randomly selected subset of schools from a list of all public and independent primary schools were invited to participate within each LGA. One hundred and fifty-six primary schools were invited during Term 4 (September to December 2013), with 39 schools consenting to participate (school-level response rate $(\mathrm{RR})=25 \%)$. Within these schools, all Grade 4 and Grade 6 students were invited $(\mathrm{n}=2357)$ with 856 parent/guardian consents received through the return of the signed parent/guardian consent form (student-level $\mathrm{RR}=36 \%$ ). In order to examine the segmented patterns of PA and ST, a subsample of students who were provided with an accelerometer is utilised in this article (see online supplementary appendix 1 for a detailed overview of accelerometry and nonaccelerometry participants).

\section{Measures and data management}

All participants completed a self-report questionnaire during class (20-35 min) which collected demographic (date of birth, gender, residential postcode, language spoken at home, country of birth and ancestry), PA and SB participation, ${ }^{21}{ }^{22}$ diet quality (N Parletta, L 
Frensham, J Peters, et al. Validation of a simple dietary questionnaire with adolescents in an Australian population. Under review 2013) ${ }^{23}$ and perceived health and well-being. ${ }^{24}$ Participants were also invited to have their height and weight measured by trained research assistants during class time (3-5 min per student). While the anthropometric measurements were taking place, a random subsample were also invited to wear an accelerometer for the proceeding 7 days. The engagement of a subsample was necessary due to the limited number of accelerometers; therefore, every second, boy and girl in Grade 4 and Grade 6 (eg, 1st Grade 6 boy and girl, 3rd Grade 6 boy and girl etc) were invited to wear an accelerometer.

Self-reported residential suburb/postcode was used to categorise individuals within quintiles of Relative Socio-economic Advantage and Disadvantage (IRSAD) which was derived from the Australian Bureau of Statistics (ABS) Socio-Economic Indexes for Areas (SEIFA) index from the 2011 Australian Census. ${ }^{19}$ Self-reported language spoken predominantly at home was used to categorise individuals into two categories (English speaking and language other than English) as a measure of culture and linguistic diversity. ${ }^{25}$ The term recognises that groups and individuals differ according to ethnicity, language, race, religion and spirituality and the term CALD is often used to describe groups that differ from the English-speaking majority (non-CALD) ${ }^{25}$

Height was measured to the nearest $0.5 \mathrm{~cm}$ using a portable stadiometer (Charder HM-200P Portstad, Charder Electronic Co, Taichung City, Taiwan) and weight to the nearest $0.1 \mathrm{~kg}$ using an electronic weight scale (A\&D Precision Scale UC-321; A7D Medical, San Jose, California, USA) without shoes and while wearing light clothing. Age and sex-specific body mass index (BMI) z-scores and weight status categories were calculated using the WHO's growth reference. ${ }^{26}$

The ActiGraph GT3X and GT3X+ accelerometer models (ActiGraph, Pensacola, Florida, USA) were utilised and participants were instructed to wear the activity monitor on the right hip during waking hours, excluding water-based and sparring activities (eg, boxing). The intergenerational issue of the differing ActiGraph accelerometer models was overcome by selecting a $15 \mathrm{~s}$ epoch and $30 \mathrm{~Hz}$ sampling rate, which has previously been shown to have strong agreement with total vertical axis counts, total vector magnitude (VM) counts and MVPA among children and adolescents. ${ }^{27}$ Non-wear-time was identified by periods in which $\geq 60 \mathrm{~min}$ of consecutive zero counts were obtained, with a 1-2 min allowance of counts between 0 and $100 .{ }^{28}$ Wear-time was calculated by subtracting non-wear-time from 24 hours. A valid day of wear was considered if $\geq 600 \mathrm{~min} /$ day $^{28}$ of wear-time was recorded over a minimum $\geq 3$ days; reliable estimates of children's PA have been observed with $\geq 600 \mathrm{~min} /$ day of monitoring over a minimum of $\geq 2$ days. ${ }^{29}$ Total vector magnitude (VM) counts per minute (counts/min) were calculated to give an indication of overall volume of PA.
The VM counts use information from three axes via the equation $\mathrm{VM}=\sqrt{(\text { Axis } 1)^{2}+(\text { Axis } 2)^{2}+(\text { Axis } 3)^{2}}$ and were calculated per epoch of time. ${ }^{30}$ Metabolic equivalent units (METs) were assigned to VM counts/min to classify the intensity of activity as: sedentary (ST) $\leq 1.5$ METs, light $(\mathrm{LPA})=1.5-2.9$ METs and moderate-to-vigorous (MVPA) $\geq 3.0$ METs $^{31}$ using the validated accelerometer cut-points developed by Romanzini et al. ${ }^{32}$ While newer accelerometer models can capture three axes of data, ${ }^{33}$ the reporting of this information is less apparent than the singular vertical axis (Axis 1).

Temporal patterns of PA and ST participation during the week were examined using three distinct timeperiods that reflected the typical cadence of the school day (before-school=8:00-8:59; during-school=9:00-15:29 and after-school=15:30-18:00). These time-periods were selected to reflect the Australian education environment as well as the time periods commonly used to define the after-school period. ${ }^{34}$ Durations spent in sedentary (ST), light (LPA) and moderate-to-vigorous (MVPA) activity within these specific temporal windows were examined as well as durations spent in daily (Monday-Sunday) activity. The contribution (proportion) of each of these distinct time-periods to overall ST, LPA and MVPA was calculated by the following formula (100/Total participation (Monday-Friday) in the respective intensity) $\times$ participation in the interested time-period and intensity (Monday-Friday)). Adherence to the Australian National Physical Activity Guidelines ${ }^{35}$ was examined using the averagexdays method, ${ }^{36}$ whereby a child is considered compliant if MVPA duration on average exceeds $\geq 60 \mathrm{~min} /$ day of MVPA.

\section{Statistical analyses}

Only participants with complete anthropometric, questionnaire and accelerometry data were included in the analyses $(n=298)$. No differences were identified in mean age, gender distribution, SEIFA quintile or weight status category between the analysis sample and those not included for analyses (non-participants), although CALD status differed significantly, suggesting that proportionally more CALD background were nonparticipants for various reasons $(\mathrm{p} \leq 0.001)$ (see online supplementary appendix 1). Statistical analyses were conducted using STATA V.12.0 (STATA Corp., College Station, Texas, USA). Initial analyses examined whether the mean BMI-z score or average MVPA duration differed between intervention and comparison participants using a multilevel mixed-effects linear regression analysis and had valid accelerometry ( $\mathrm{n}=298$ participants). No significant differences were detected by condition (intervention vs comparison), supporting the subsequent analyses on combined cross-sectional data.

Independent sample t-tests examined if gender differences were evident as well as differences in weight status category for demographic and behavioural variables, Cohen's (d) effect size for independent samples was also calculated and interpreted as: 0.0-0.19 (trivial effect), 
0.20-0.49 (small effect), 0.50-0.79 (medium effect) and 0.80 or higher (large effect). ${ }^{37}$ Pearson's $\chi^{2}$ tests were used to examine differences in proportions. A series of independent linear regression analyses examined the relationship between the dependent variables (MVPA, LPA, ST) and weight status (healthy weight (reference) and overweight/obesity) during-school, while controlling for the potential influences of age, socioeconomic position ((SEP), highest 5th quintile (reference)) study condition (intervention (reference) or comparison) and cluster-based sampling (with LGA utilised as the cluster unit). The regression analyses were stratified by gender since gender is a significant predictor of PA among chil$\operatorname{dren}^{8}{ }^{38}$ and separate models were used for MVPA, LPA and ST because SB can be independent of PA participation. ${ }^{39}$ Significance was set at $\mathrm{p}<0.05$ for all analyses.

\section{RESULTS}

Table 1 presents the demographic characteristics of participants with complete accelerometry data by gender and weight status. No significant gender or weight status differences were observed for age, CALD status, SEIFA quintile, accelerometer wear-time and number of valid weekdays or weekend days of accelerometer monitoring. However, among boys, the mean BMI-z score was higher, daily activity counts/min and average daily MVPA duration were higher and daily ST was lower compared with girls (all, $\mathrm{p} \leq 0.05$ ). Cohen's effect size demonstrated large effect for gender differences for MVPA duration only $(\mathrm{d}=1.0) .{ }^{37}$ Girls with overweight/obesity engaged in significantly lower levels of daily LPA, MVPA and higher levels of ST than girls in the healthy weight range, with small effect sizes observed $(\mathrm{d}=0.26-0.48)$. On average, participants spent $\sim 8$ hours/day engaged in ST, 3 hours/ day in LPA and 1.5 hours/day in MVPA regardless of gender or weight status.

Participation in PA and ST across the three specific school-day time-periods (before-school (8:00-9:00), during-school (9:00-15:30) and after-school (15:3018:00)) are presented in table 2 by gender and graphically in figure $1 \mathrm{~A}-\mathrm{C}$ by weight status and gender. Bivariate analyses revealed significant gender difference in MVPA participation between boys and girls before and duringschool which was confirmed with medium $(\mathrm{d}=0.69)$ and large effect sizes $(\mathrm{d}=1.05)$, respectively. No significant differences between boys in the healthy weight range and those in the overweight/obese range within the before-school, during-school or after-school period for average activity counts, LPA, MVPA or ST duration. In contrast, among girls, significant differences were evident between the weight status categories within the during-school period. Those with overweight/obesity had significantly less mean LPA and MVPA duration and greater ST duration than girls with healthy weight during-school (all, $\mathrm{p} \leq 0.05$ ). Gender-specific differences were also evident for average activity counts, LPA, MVPA and ST participation at various times throughout the day $(\mathrm{p}<0.01)$. Additional analyses examined the proportion each time period contributed to overall participation in each activity intensity. These analyses revealed that the before-school period explained the smallest proportion of overall PA and ST (7-8\% of total LPA, $7-9 \%$ of total MVPA and 5\% of total ST), the during-school period the greatest proportion (48-53\% of total LPA, 49-53\% of total MVPA and 44-47\% of total ST), followed by the after-school period $(18-20 \%$ of total LPA, $19-20 \%$ of total MVPA and $17-18 \%$ of total ST) (see online supplementary appendix 2).

Multivariable linear regression analyses, stratified by gender and adjusted for a range of covariates, were conducted to examine if weight status explained differences in mean activity counts, LPA, MVPA and ST participation across the school day as it was the greatest contributor to PA and SB participation (tables 3 and 4). Significant weight status differences were only evident for average activity counts, with boys with overweight/ obesity having significantly lower counts $/ \min (\beta=-65.4$; $95 \%$ CI -119.99 to -10.79 counts $/ \mathrm{min}$ ). Among girls, those with overweight/obesity spent less time in LPA ( $\beta=$ $-12.0 ; 95 \%$ CI -19.40 to $-4.61 \mathrm{~min} /$ day), MVPA ( $\beta=$ $-5.7 ; 95 \%$ CI -11.04 to $-0.44 \mathrm{~min} /$ day) and more time in ST ( $\beta=20.2 ; 95 \%$ CI 9.79 to $30.64 \mathrm{~min} /$ day) than girls with healthy weight. Significant age differences were also evident for both genders and are presented in the table.

\section{DISCUSSION}

This study investigated the relationship between weight status and PA and SB participation across specific schoolday time-periods among a sample of disadvantaged Victorian primary school boys and girls. Almost all participants met the PA guidelines $(\geq 86 \%)^{35}$ using the averagexdays method, ${ }^{36}$ despite more than one in four children being classified as overweight or obese. In relation to the first research question which aimed to examine the composition of PA and ST participation across the school day; the during-school period (9:0015:30) saw the greatest accumulation of LPA and MVPA for boys and girls. The second research question aimed to examine the influence of weight status on the composition of PA and ST across the school day by gender, with no significant weight status differences found for before-school and after-school periods, regardless of gender. However, bivariate and adjusted multiple regression models found girls with overweight/obesity engaged in significantly less LPA and MVPA, and greater ST during-school than their peers with healthy weight $(p \leq 0.05)$. In addition, boys with overweight/obesity had significantly lower mean activity counts than boys with healthy weight during-school $(\mathrm{p} \leq 0.05)$. The above findings from this study highlight the importance of improving $\mathrm{SB}$ and $\mathrm{PA}$ in childhood obesity prevention efforts and the importance of schools as possible healthenhancing environments among children from disadvantaged areas. 
Table 1 Descriptive characteristics and unadjusted physical activity and sedentary behaviour patterns of participants $($ mean $+95 \% \mathrm{Cl})$

\begin{tabular}{|c|c|c|c|c|c|c|c|c|c|c|c|}
\hline & & \multirow[b]{2}{*}{$\mathbf{N}$} & \multirow{2}{*}{$\begin{array}{l}\text { Total } \\
(\text { Mean } \pm 95 \% \mathrm{Cl})\end{array}$} & \multicolumn{2}{|l|}{ Difference, boys vs girls } & \multirow[b]{2}{*}{$\mathbf{N}$} & \multirow{2}{*}{$\begin{array}{l}\text { Healthy weight† } \\
(\text { Mean } \pm 95 \% \mathrm{Cl})\end{array}$} & \multirow[b]{2}{*}{$\mathbf{N}$} & \multirow{2}{*}{$\begin{array}{l}\text { Overweight or obese } \\
(\text { Mean } \pm 95 \% \mathrm{Cl})\end{array}$} & \multicolumn{2}{|c|}{$\begin{array}{l}\text { Difference (healthy weight vs } \\
\text { overweight or obesity) }\end{array}$} \\
\hline & & & & (Mean diff $\pm 95 \%$ Cl) & $\begin{array}{l}\text { Effect } \\
\text { size (d) }\end{array}$ & & & & & (Mean diff $\pm 95 \% \mathrm{Cl}$ ) & $\begin{array}{l}\text { Effect } \\
\text { size (d) }\end{array}$ \\
\hline \multicolumn{12}{|l|}{ Age (years) } \\
\hline Boys & (M) & 130 & $11.3(11.10$ to 11.48$)$ & $0.1(-0.12$ to 0.37$)$ & 0.12 & 82 & $11.4(11.18$ to 11.64$)$ & 48 & $11.1(10.77$ to 11.41$)$ & $0.3(-0.06$ to 0.71$)$ & 0.30 \\
\hline Girls & $(F)$ & 168 & $11.2(11.01$ to 11.32$)$ & & & 124 & 11.1 (10.92 to 11.29$)$ & 44 & $11.3(11.04$ to 11.64$)$ & $-0.2(-0.59$ to 0.12$)$ & -0.23 \\
\hline \multicolumn{12}{|l|}{ Ethnicity-language } \\
\hline \multirow{2}{*}{$\begin{array}{l}\text { (Language other } \\
\text { than English) }\end{array}$} & $(\mathrm{M})$ & 17 & $13.60 \%$ & & & 8 & $10.26 \%$ & 9 & $19.15 \%$ & & \\
\hline & $(F)$ & 21 & $12.50 \%$ & & & 16 & $12.90 \%$ & 5 & $11.36 \%$ & & \\
\hline \multicolumn{12}{|l|}{ SEIFA quintile (\%) } \\
\hline \multirow[t]{2}{*}{ Lowest quintile } & (M) & 37 & $30.33 \%$ & & & 25 & $32.47 \%$ & 12 & $26.67 \%$ & & \\
\hline & $(F)$ & 33 & $20.25 \%$ & & & 27 & $22.13 \%$ & 6 & $14.63 \%$ & & \\
\hline \multirow[t]{2}{*}{ BMI-z } & (M) & 130 & 0.6 (0.41 to 0.84$)$ & 0.3 (0.49 to 0.58$)$ & 0.27 & 82 & $-0.1(-0.31$ to 0.03$)$ & 48 & $1.9(1.77 \text { to } 2.10)^{\Phi \Phi \Phi ~}$ & $-2.1(-2.33$ to -1.82$)$ & -2.95 \\
\hline & $(F)$ & 168 & $0.3(0.15 \text { to } 0.48)^{*}$ & & & 124 & $-0.2(-0.31$ to -0.04$)$ & 44 & $1.7(1.51$ to 1.85$)+++$ & $-1.9(-2.10$ to -1.61$)$ & -2.59 \\
\hline \multicolumn{12}{|l|}{ Valid wear (days) } \\
\hline \multirow[t]{2}{*}{ Valid weekdays } & (M) & 130 & 3.9 (3.75 to 4.08$)$ & $0.1(-0.13$ to 0.33$)$ & 0.10 & 82 & 3.8 (3.64 to 4.05$)$ & 48 & 4.0 (3.76 to 4.32$)$ & $-0.2(-0.54$ to 0.14$)$ & -0.21 \\
\hline & $(F)$ & 168 & 3.8 (3.66 to 3.97$)$ & & & 124 & $3.8(3.64$ to 4.00$)$ & 44 & 3.8 (3.45 to 3.14$)$ & $0.0(-0.33$ to 0.39$)$ & 0.03 \\
\hline \multirow[t]{2}{*}{ Valid weekend days } & (M) & 130 & $1.3(1.15$ to 1.43$)$ & $0.0(-0.17$ to 0.18$)$ & 0.01 & 82 & $1.3(1.17$ to 1.51$)$ & 48 & $1.2(0.99$ to 1.43$)$ & $0.1(-0.14$ to 0.41$)$ & 0.17 \\
\hline & $(F)$ & 168 & $1.3(1.17$ to 1.40$)$ & & & 124 & $1.3(1.20$ to 1.46$)$ & 44 & $1.2(0.91$ to 1.40$)$ & $0.2(-0.09$ to 0.43$)$ & 0.23 \\
\hline \multirow{2}{*}{$\begin{array}{l}\text { Daily wear-time } \\
\text { (min/day) } \\
\text { (Monday-Sunday) }\end{array}$} & (M) & 130 & 789.4 (774.99 to 803.71$)$ & $-4.0(-23.33$ to 15.37$)$ & -0.05 & 82 & 779.7 (763.42 to 796.01$)$ & 48 & 805.8 (778.43 to 833.19$)$ & $-26.1(-55.62$ to 2.44$)$ & -0.32 \\
\hline & $(F)$ & 168 & 793.3 (780.35 to 806.31$)$ & & & 124 & 792.4 (775.95 to 808.86$)$ & 44 & 796.0 (777.46 to 814.44$)$ & $-3.6(-33.16$ to 26.07$)$ & -0.04 \\
\hline \multirow{2}{*}{$\begin{array}{l}\text { Daily activity counts } \\
\text { (counts/min) } \ddagger \\
\text { (Monday-Sunday) }\end{array}$} & (M) & 130 & 261.3 (244.28 to 278.31$)$ & 33.5 (12.15 to 54.85$)$ & 0.36 & 82 & 269.1 (247.63 to 290.57$)$ & 48 & 248.0 (219.45 to 276.48$)$ & $21.1(-14.06$ to 56.34$)$ & 0.22 \\
\hline & $(F)$ & 168 & $227.8(214.29 \text { to } 241.30)^{\star \star}$ & & & 124 & 233.8 (217.69 to 249.85 ) & 44 & 210 (186.00 to 235.90$)$ & 22.8 ( -7.79 to 53.43$)$ & 0.26 \\
\hline \multirow{2}{*}{$\begin{array}{l}\text { Daily sedentary } \\
\text { (min/day) } \ddagger \\
\text { (Monday-Sunday) }\end{array}$} & (M) & 130 & 479.0 (463.41 to 494.57$)$ & $-24.3(-45.20$ to -3.46$)$ & -0.27 & 82 & $469.0(450.72$ to 487.17$)$ & 48 & 496.1 (467.41 to 524.88 ) & $-27.2(-59.26$ to 4.86$)$ & -0.31 \\
\hline & $(F)$ & 168 & $503.3(489.37 \text { to } 517.26)^{*}$ & & & 124 & 495.0 (478.00 to 511.93 ) & 44 & $526.9(503.86$ to 549.85$)+$ & $-31.9(-63.32$ to -0.46$)$ & -0.35 \\
\hline \multirow{2}{*}{$\begin{array}{l}\text { Daily LPA (min/day) } \ddagger \\
\text { (Monday-Sunday) }\end{array}$} & (M) & 130 & 192.7 (187.30 to 198.12$)$ & $-7.9(-15.76$ to 0.7$)$ & -0.23 & 82 & $191.3(184.13$ to 198.54$)$ & 48 & 195.1 (186.80 to 203.33 ) & $-3.7(-14.97$ to 7.51$)$ & -0.12 \\
\hline & $(F)$ & 168 & 200.6 (194.96 to 206.15 ) & & & 124 & 204.6 (198.25 to 210.95$)$ & 44 & $189.2(177.74$ to 200.57$)+$ & 15.5 (2.90 to 28.00$)$ & 0.43 \\
\hline \multirow{2}{*}{$\begin{array}{l}\text { Daily MVPA (min/day)f } \\
\text { (Monday-Sunday) }\end{array}$} & (M) & 130 & 116.7 (111.58 to 121.84$)$ & 28.3 (21.80 to 34.70$)$ & 1.01 & 82 & $118.5(112.03$ to 124.97$)$ & 48 & 113.7 (105.02 to 122.29$)$ & $4.9(-5.75$ to 15.48$)$ & 0.16 \\
\hline & $(F)$ & 168 & $88.5(84.37 \text { to } 92.56)^{\star \star \star}$ & & & 124 & 91.8 (86.97 to 96.60$)$ & 44 & $79.1(71.73$ to 86.43$)++$ & 12.7 (3.58 to 21.85 ) & 0.48 \\
\hline $\begin{array}{l}\text { Meeting MVPA } \\
\text { guidelines }\end{array}$ & $(\mathrm{M})$ & 126 & $96.9 \%$ & & & 80 & $97.6 \%$ & 46 & $95.8 \%$ & & \\
\hline $\begin{array}{l}\text { (Average method \%) } \\
\text { (Monday-Sunday) }\end{array}$ & $(F)$ & 144 & $85.7 \%$ ** & & & 112 & $90.3 \%$ & 32 & $72.7 \%++$ & & \\
\hline $\begin{array}{l}\text { Independent-sample } \\
\text { was calculated for m } \\
\text { differed significantly } \\
\text { †Healthy weight cate } \\
\text { †Based on }>600 \text { min } \\
\text { SEIFA, Index of Rela }\end{array}$ & girl & 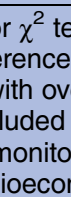 & $\begin{array}{l}\text { Ised to determine signific } \\
\text { catio data; boys with heal } \\
\text { ight/obesity with }+p \leq 0.0 \\
\text { erweight. } \\
\text { over } \geq 3 \text { days. }\end{array}$ & $\begin{array}{l}\text { mean or proportional } \\
\text { weight boys differed si } \\
+p \leq 0.01 ;+++p \leq 0.001 \text { ) }\end{array}$ & $\begin{array}{l}\text { alrteren } \\
\text { gnifical } \\
\text {; }\end{array}$ & 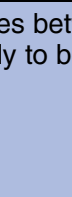 & $\begin{array}{l}\text { ween boys and girls } 0 \\
\text { oys with overweight/o }\end{array}$ & & $\begin{array}{l}\text { vith }{ }^{*} p \leq 0.05 ;{ }^{* *} p \leq 0.01 ;{ }^{* * *} p \leq 0.05 ;{ }^{\Phi}{ }^{\Phi} p \leq 0.001 ; \text { Gir } \\
\end{array}$ & $\begin{array}{l}0.001 \text {; Cohen's } \mathrm{d} \text { eff } \\
\text { with healthy weight }\end{array}$ & \\
\hline
\end{tabular}


Table 2 Before-school physical activity and sedentary behaviour participation by gendert

\begin{tabular}{|c|c|c|c|c|}
\hline & \multirow[b]{2}{*}{$\mathbf{N}$} & \multirow{2}{*}{$\begin{array}{l}\text { Total } \\
(\text { Mean } \pm 95 \% \mathrm{Cl})\end{array}$} & \multicolumn{2}{|l|}{ Difference Boys vs Girls } \\
\hline & & & (Mean Diff $\pm 95 \% \mathrm{Cl}$ ) & Effect size (d) \\
\hline \multicolumn{5}{|c|}{ Before-school (8:00-9:00) Monday-Friday } \\
\hline Boys & 130 & 466.6 (425.59 to 507.53$)$ & $91.2(42.69 \text { to } 139.68)^{\star \star \star}$ & 0.43 \\
\hline Girls & 168 & 375.4 (345.56 to 404.16$)$ & & \\
\hline \multicolumn{5}{|c|}{ Sedentary (min/day) $\dagger$} \\
\hline \multicolumn{5}{|c|}{ LPA (min/day) $\dagger$} \\
\hline Boys & 130 & $14.0(13.24$ to 14.80$)$ & $-0.82(-1.90$ to 0.26$)$ & -0.18 \\
\hline Girls & 168 & $14.8(14.10$ to 15.57$)$ & & \\
\hline \multicolumn{5}{|c|}{ MVPA (min/day) $\dagger$} \\
\hline Boys & 130 & 9.6 (8.78 to 10.54$)$ & $3.0(2.00 \text { to } 4.03)^{\star \star \star}$ & 0.69 \\
\hline Girls & 168 & 326.2 (301.09 to 351.20$)$ & & \\
\hline \multicolumn{5}{|c|}{ Sedentary (min/day) $\dagger$} \\
\hline Boys & 130 & 212.7 (207.49 to 217.83 ) & $-14.6(-21.74 \text { to }-7.53)^{\star \star *}$ & -0.47 \\
\hline Girls & 168 & 227.3 (222.46 to 232.13$)$ & & \\
\hline \multicolumn{5}{|c|}{ LPA (min/day) $\dagger$} \\
\hline Boys & 130 & 101.7 (98.46 to 104.93$)$ & $-1.4(-6.21$ to 3.41$)$ & -0.06 \\
\hline Girls & 168 & 103.1 (99.66 to 106.53$)$ & & \\
\hline \multicolumn{5}{|c|}{ MVPA (min/day) $\dagger$} \\
\hline Boys & 130 & 61.8 (58.85 to 64.73$)$ & $16.6(12.98 \text { to } 20.25)^{\star \star \star}$ & 1.05 \\
\hline Girls & 168 & 45.2 (42.91 to 47.44$)$ & & \\
\hline \multicolumn{5}{|c|}{ After-school (15:30-18:00) Monday-Friday } \\
\hline Girls & 168 & 39.7 (38.17 to 41.26$)$ & & \\
\hline \multicolumn{5}{|c|}{ MVPA (min/day) $\dagger$} \\
\hline Boys & 130 & 23.6 (21.77 to 25.51$)$ & $4.8(2.54 \text { to } 7.00)^{\star * *}$ & 0.49 \\
\hline Girls & 168 & $18.9(17.54$ to 20.21$)$ & & \\
\hline
\end{tabular}

Consistent with previous international research, this study found that Australian girls engaged in significantly less daily (total) MVPA than boys, which was supported by the strong effect size. ${ }^{88}$ In addition, girls engaged in more ST than boys in total, with medium effect size, which has not previously demonstrated consistent gender differentials among children. ${ }^{7} 8$ Gender differences in total and types of PA accelerate from observance at $\sim 10$ years of age,$^{40}$ which our results support, that girls are not closing this activity gap. When examining gender differences in participation within school, similar findings were observed and appear to be consistent with current international literature that suggests girls engage in less MVPA and more ST during-school hours (large and medium effect size, respectively), ${ }^{17} 18$ and no significant difference in LPA. ${ }^{18}$ One such study among 380 children (aged 8-11 years) from Vancouver, Canada, found that during-school (9:00-15:00), boys and girls engaged in on average 63 and $53 \mathrm{~min} /$ day of MVPA, 56 and $54 \mathrm{~min} /$ day of LPA and 246 and $260 \mathrm{~min} /$ day of ST, respectively. ${ }^{18}$ These findings are largely comparable with the current study, although it would appear that this Australian sample engaged in more LPA in preference to ST, although this may be simply reflect the differing classification of the school day $(9: 00-15: 30)$ in the present study. 
Figure 1 (A) Before-school physical activity and sedentary behaviour participation by weight status and gender (mean and 95\% Cl). (B) During-school physical activity and sedentary behaviour participation by weight status and gender (mean and 95\% Cl). (C) After-school physical activity and sedentary behaviour participation by weight status and gender (mean and $95 \% \mathrm{Cl}$ ).

\section{A}
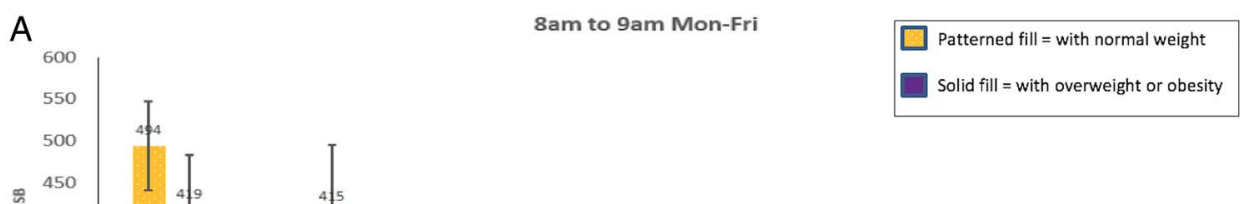

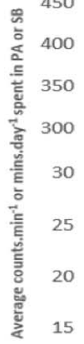

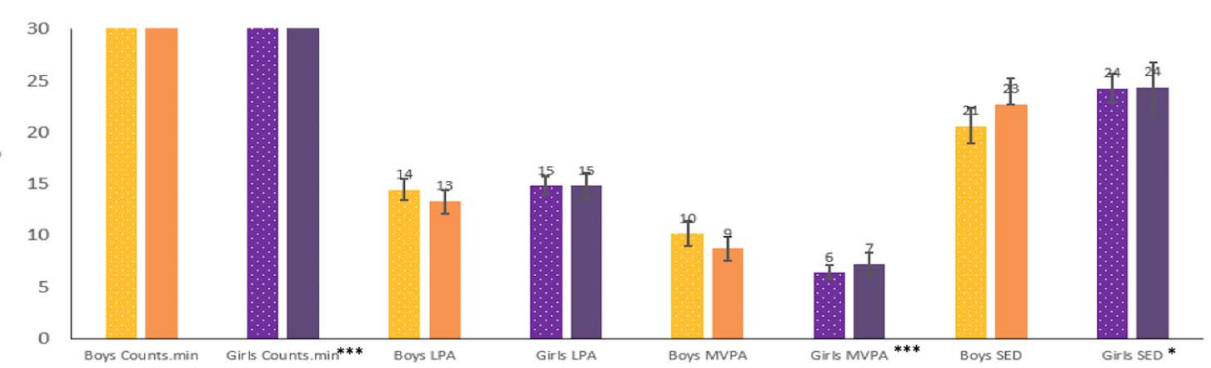

B

9am to 3:30pm Mon-Fri
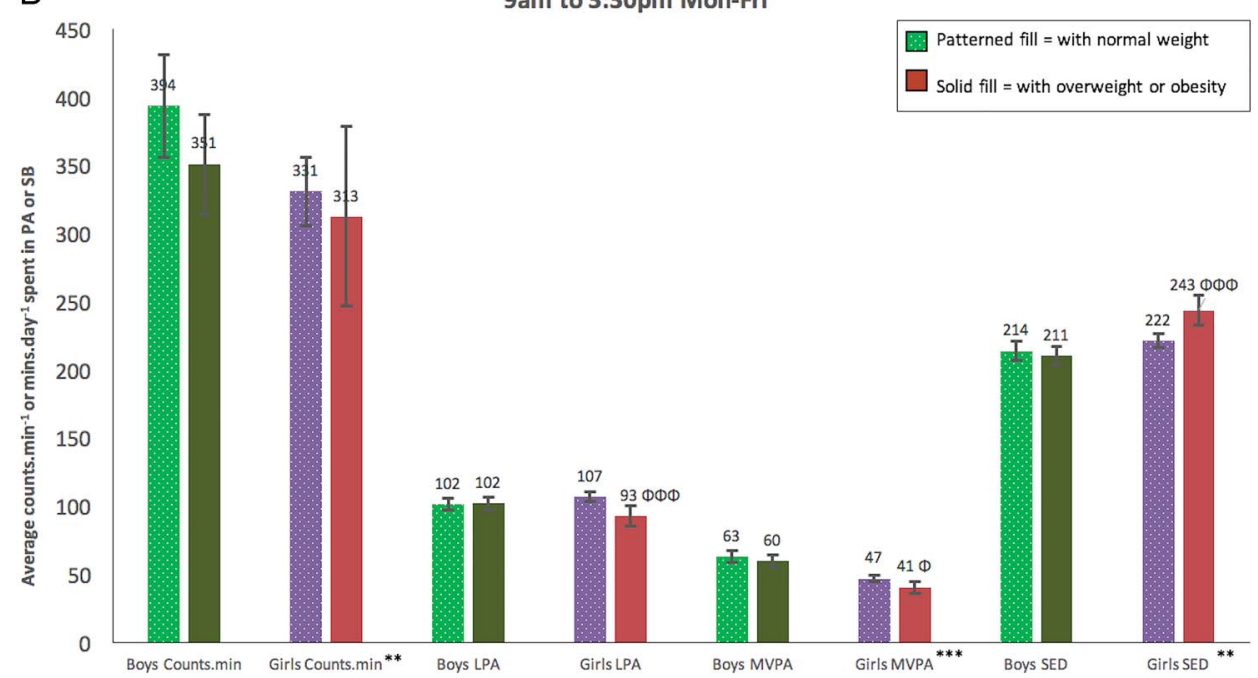

C
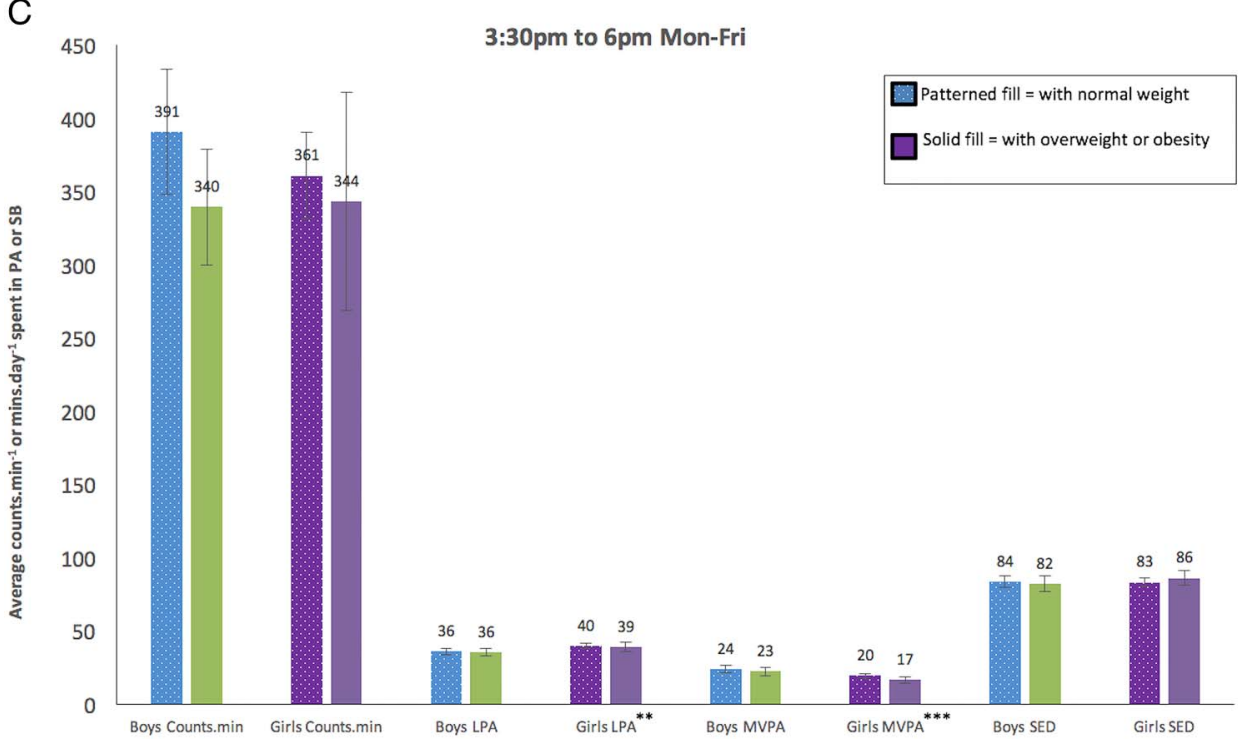
Table 3 Multiple regression analysis of during-school physical activity and sedentary behaviours participation among boys

\begin{tabular}{|c|c|c|c|c|c|c|c|c|c|c|c|c|}
\hline \multirow[b]{2}{*}{ Variable } & \multicolumn{3}{|c|}{ Counts/min } & \multicolumn{3}{|l|}{ LPA } & \multicolumn{3}{|l|}{ MVPA } & \multicolumn{3}{|l|}{ SED } \\
\hline & $\bar{\beta}$ & $95 \% \mathrm{Cl}$ & p Value & $\bar{\beta}$ & $95 \% \mathrm{Cl}$ & p Value & $\bar{\beta}$ & $95 \% \mathrm{Cl}$ & p Value & $\overline{\boldsymbol{\beta}}$ & $95 \% \mathrm{Cl}$ & p Value \\
\hline Weight status & REF & REF & REF & REF & REF & REF & REF & REF & REF & REF & REF & REF \\
\hline Overweight/obese (1) & -65.39 & $(-119.99$ to -10.79$)$ & 0.019 & -2.0 & $(-9.28$ to 5.31$)$ & 0.590 & -5.4 & $(-12.07$ to 1.27$)$ & 0.112 & 0.66 & $(-10.90$ to 12.22$)$ & 0.910 \\
\hline Age (years) & -21.84 & $(-46.32$ to 2.64$)$ & 0.08 & -4.7 & (-7.96 to 1.43$)$ & 0.005 & -1.63 & $(-4.62$ to 1.37$)$ & 0.284 & 5.11 & $(-0.071$ 10.30) & 0.053 \\
\hline SEIFA quintile (highest) & REF & REF & REF & REF & REF & REF & REF & REF & REF & REF & REF & REF \\
\hline 4 th & -31.62 & $(-171.90$ to 108.66$)$ & 0.656 & -2.0 & $(-20.74$ to 16.73$)$ & 0.832 & -6.48 & $\begin{array}{l}(-23.62 \text { to } \\
10.67)\end{array}$ & 0.456 & 1.26 & $(-28.43$ to 30.95$)$ & 0.933 \\
\hline $3 r d$ & -1.98 & $(-156.15$ to 152.20$)$ & 0.980 & -5.1 & $(-25.73$ to 15.45$)$ & 0.622 & -12.17 & $(-31.01$ to 6.67$)$ & 0.203 & 4.64 & $(-28.00$ to 37.27$)$ & 0.779 \\
\hline 2nd & 7.44 & $(-130.77$ to 145.66$)$ & 0.915 & -4.9 & $(-23.37$ to 13.55$)$ & 0.599 & -9.07 & $(-25.96$ to 7.82$)$ & 0.290 & 9.80 & $(-19.46$ to 39.05$)$ & 0.508 \\
\hline Lowest & -69.96 & $(-204.53$ to 64.61$)$ & 0.305 & -9.0 & $(-26.94$ to 9.01$)$ & 0.325 & -9.05 & $(-25.49$ to 7.40$)$ & 0.278 & 10.80 & $(-17.68$ to 39.29$)$ & 0.454 \\
\hline $\begin{array}{l}\text { Language (ESP (0) vs } \\
\text { LOTE (1)) }\end{array}$ & 51.93 & $(-25.34$ to 129.18$)$ & 0.186 & 4.5 & $(-5.82$ to 14.81$)$ & 0.390 & 3.85 & $(-5.59$ to 13.29$)$ & 0.421 & -12.98 & $(-29.33$ to 3.37$)$ & 0.118 \\
\hline $\begin{array}{l}\text { LGA (school clustering } \\
\text { unit) }\end{array}$ & -1.48 & $(-6.08$ to 3.12$)$ & 0.534 & -0.2 & $(-0.82$ to 0.41$)$ & 0.506 & -0.42 & $(-0.98$ to 0.14$)$ & 0.143 & 0.24 & $(-0.73$ to 1.21$)$ & 0.625 \\
\hline $\begin{array}{l}\text { Condition (Int (0) vs Cont } \\
\text { (1)) }\end{array}$ & 7.62 & $(-47.86$ to 63.10$)$ & 0.786 & -0.9 & $(-8.32$ to 6.50$)$ & 0.808 & -3.04 & $(-9.82$ to 3.74$)$ & 0.376 & 8.99 & $(-2.76$ to 20.73$)$ & 0.132 \\
\hline $\begin{array}{l}\text { Constant } \\
\mathrm{R}^{2}\end{array}$ & $\begin{array}{l}630.15 \\
0.11\end{array}$ & (324.66 to 935.64$)$ & 0.000 & $\begin{array}{l}159.2 \\
0.10\end{array}$ & (118.43 to 200.04 ) & 0.000 & $\begin{array}{l}92.98 \\
0.08\end{array}$ & (55.65 to 130.31$)$ & 0.000 & $\begin{array}{l}156.39 \\
0.09\end{array}$ & (91.73 to 221.05 ) & 0.000 \\
\hline Adj $R^{2}$ & 0.04 & & & 0.02 & & & 0.01 & & & 0.02 & & \\
\hline SEE (MRSE) & 140.66 & & & 18.79 & & & 17.19 & & & 29.77 & & \\
\hline
\end{tabular}

\begin{tabular}{|c|c|c|c|c|c|c|c|c|c|c|c|c|}
\hline \multirow[b]{2}{*}{ Variable } & \multicolumn{3}{|c|}{ Counts/min } & \multicolumn{3}{|l|}{ LPA } & \multicolumn{3}{|l|}{ MVPA } & \multicolumn{3}{|l|}{ ST } \\
\hline & $\overline{\boldsymbol{\beta}}$ & $95 \% \mathrm{Cl}$ & p Value & $\overline{\boldsymbol{\beta}}$ & $95 \% \mathrm{Cl}$ & p Value & $\overline{\boldsymbol{\beta}}$ & $95 \% \mathrm{Cl}$ & p Value & $\overline{\boldsymbol{\beta}}$ & $95 \% \mathrm{Cl}$ & p Value \\
\hline Weight status & REF & REF & REF & & & & & & & & & \\
\hline Overweight/obese (1) & -22.74 & $(-81.81$ to 36.34$)$ & 0.448 & -12.0 & $(-19.40$ to -4.61$)$ & 0.002 & -5.74 & $(-11.04$ to -0.44$)$ & 0.034 & 20.21 & (9.79 to 30.64$)$ & 0.000 \\
\hline Age (years) & -22.06 & $(-46.88$ to 2.76$)$ & 0.081 & -7.1 & $(-10.24$ to -4.04$)$ & 0.000 & -2.12 & $(-4.34$ to 0.11$)$ & 0.062 & 8.56 & (4.18 to 12.94$)$ & 0.000 \\
\hline $\begin{array}{l}\text { SEIFA quintile } \\
\text { (highest=5th) }\end{array}$ & REF & REF & REF & REF & REF & REF & REF & REF & REF & REF & REF & REF \\
\hline 4 th & -83.49 & $(-200.68$ to 33.71$)$ & 0.161 & -4.3 & $(-18.92$ to 10.41$)$ & 0.568 & -7.04 & $(-17.55$ to 3.48$)$ & 0.188 & 1.69 & $(-18.99$ to 22.38$)$ & 0.872 \\
\hline 3rd & -20.18 & $(-144.87$ to 104.52$)$ & 0.750 & 4.5 & $(-11.11$ to 20.10$)$ & 0.570 & -6.36 & ( -17.55 to 4.82$)$ & 0.263 & -8.99 & $(-31.00$ to 13.02$)$ & 0.421 \\
\hline 2nd & -60.27 & $(-177.84$ to 57.30$)$ & 0.313 & -12.2 & ( -26.89 to 2.53$)$ & 0.104 & -10.3 & $(-20.85$ to 0.25$)$ & 0.056 & 15.92 & $(-4.83$ to 36.67$)$ & 0.132 \\
\hline Lowest $=1 \mathrm{st}$ & -69.53 & $(-188.01$ to 48.96$)$ & 0.248 & -7.1 & $(-21.91$ to 7.75$)$ & 0.347 & -5.75 & $(-16.38$ to 4.88$)$ & 0.287 & 5.79 & $(-15.13$ to 26.70$)$ & 0.585 \\
\hline $\begin{array}{l}\text { Language (ESP (0) vs } \\
\text { LOTE (1) }\end{array}$ & -88.05 & $(-164.49$ to -11.61$)$ & 0.024 & -0.8 & $(-10.37$ to 8.76$)$ & 0.868 & -5.95 & $(-12.81$ to 0.91$)$ & 0.089 & -2.91 & $(-16.40$ to 10.58$)$ & 0.671 \\
\hline $\begin{array}{l}\text { LGA (school } \\
\text { clustering unit) }\end{array}$ & 2.81 & $(-1.91$ to 7.52$)$ & 0.241 & -0.1 & $(-0.543$ to 0.637$)$ & 0.875 & -0.06 & $(-0.49$ to 0.36$)$ & 0.769 & 0.01 & $(-0.82$ to 0.85$)$ & 0.973 \\
\hline $\begin{array}{l}\text { Condition (Int (0) vs } \\
\text { Cont (1)) }\end{array}$ & 41.09 & $(-12.67$ to 94.86$)$ & 0.133 & 5.1 & $(-1.66$ to 11.80$)$ & 0.139 & 1.57 & $(-3.25$ to 6.40$)$ & 0.520 & -2.08 & $(-11.57$ to 7.41$)$ & 0.665 \\
\hline $\begin{array}{l}\text { Constant } \\
\mathrm{R}^{2}\end{array}$ & $\begin{array}{l}684.77 \\
0.08\end{array}$ & (369.79 to 999.76 ) & 0.000 & $\begin{array}{l}189.7 \\
0.22\end{array}$ & (150.27 to 229.11 ) & 0.000 & $\begin{array}{l}84.15 \\
0.10\end{array}$ & (55.89 to 112.41 ) & 0.000 & $\begin{array}{l}125.51 \\
0.22\end{array}$ & (69.91 to 181.11 ) & 0.000 \\
\hline Adj $R^{2}$ & 0.03 & & & 0.18 & & & 0.05 & & & 0.18 & & \\
\hline SEE (MRSE) & 163.51 & & & 20.46 & & & 14.67 & & & 28.86 & & \\
\hline
\end{tabular}

Significant findings in bold. 
This article extends the current knowledge base by examining the gender-specific association of weight status on LPA, MVPA and ST throughout defined periods of the school day; and is believed to be the first study of its type among Australian school children. No significant differences were observed between children who were within the healthy weight range and those with overweight/obesity for before-school or after-school LPA, MVPA or ST participation in the bivariate and multivariable analyses. However, the associations between duringschool participation and weight status differed significantly among boys and girls. Compared with their peers with healthy weight, boys with overweight/obesity engaged in significantly less average counts/min and girls with overweight/obesity engaged in approximately $-12 \mathrm{~min} /$ day less LPA and $-6 \mathrm{~min} /$ day less MVPA and +20 min/day more ST after adjustment for covariates. The observation that weight status was significantly associated with PA participation throughout the school day among children is supported by a large multinational European study. ${ }^{17}$ The ENERGY study (Belgium, Greece, Hungary, the Netherlands, Switzerland) among 1025 children (aged 10-12 years) with complete accelerometry data found weight status predicted MVPA but not ST participation. ${ }^{17}$ It was found that children with overweight/ obesity spent significantly less time $(4 \%$ vs $5 \%, \mathrm{p} \leq 0.01)$ within the school-day engaged in MVPA compared with children with healthy weight. A country-specific effect for the Netherlands was observed for ST, with children with overweight/obesity engaging in more ST $(70 \%$ vs $66 \%$, $\mathrm{p} \leq 0.05)$ compared with children with healthy weight. These findings support our observances of differences in during-school participation by weight status, although of note is the observance that European children engaged in very little amounts of MVPA during-school $(16 \pm 9 \mathrm{~min} /$ day) compared with the current Australian sample (41$63 \mathrm{~min}$ /day). Varying country-specific differences, including seasonal differences, may be driving this observation as well as the varying accelerometry data handling and inclusion criteria employed in both studies.

We found that children recorded less activity afterschool than during-school, which is in contrast to the international notion that the 'After-school' period is a critical window for children's PA and can reflect up to $50 \%$ of PA engagement. ${ }^{41}$ It is hypothesised that since children in the current study were sampled from communities that have been specifically identified as at-risk areas for chronic disease, the feasibility of after-school PA participation is realistically limited due to a variety of individual, environmental and psychosocial factors (eg, costs, availability of transport to and from, parental-work commitments). For these communities, the school environment appears to be a critical setting for PA to be provided within school hours. Lessons learnt from South Australian children (aged 10-13 years) ${ }^{42}$ identified that the key barriers to after-school PA were safety for afterschool active transport, distances to engage in PA opportunities and weather. Additionally, students identified perceived competence, enjoyment, being active with friends, school sport in preference to community sport due to distance, bullying, parental rules regarding participation and lack of time also impacted on after-school PA participation. ${ }^{42}$ More research is therefore needed to identify the key facilitators and barriers to during-school and after-school PA among children from disadvantaged communities to identify and implement possible solutions, particularly for girls.

Several limitations should be considered alongside the findings from this study, including assumptions underlying cross-sectional data. First, the analyses sample emerged from a subsample of participants involved in the wider Healthy Together Victoria and Childhood Obesity study who were randomly assigned accelerometers due to the limited number available. Examination of this selection bias showed no significant difference between the included study sample and those excluded for insufficient wear, those excluded for lost/accelerometry error and those not given an accelerometer in mean age, gender distribution, SEIFA quintile or weight status. A significant difference was found for CALD background and participation/non-participation category, but this difference is likely to relate to the fact that 32 accelerometers were initialised incorrectly (set to 1-day instead of 7-day of monitoring) at one culturally and linguistically diverse primary school. However, the influence of nonparticipation bias can never be eliminated. Second, the usage of accelerometers involved many data-handling and management techniques which can directly influence the reported duration spent in intensities of $\mathrm{PA}^{43}$ as they are not standardised. ${ }^{44}$ The authors have opted for fulldisclosure of all data handling and management techniques to increase the transparency of the achieved results. Specifically, we classified MVPA as $\geq 3$ METs and used VM counts to classify activity intensity, as was done in the Romanzini equations. ${ }^{32}$ Future research should look at the development of age-specific activity intensity cut-points using VM counts as there is evidence to suggest that energy expenditure varies by age and pubertal status. ${ }^{45}$ Finally, the participants are drawn from communities selected for their high rates of chronic disease and levels of socioeconomic disadvantage,,$^{20}$ and thus are not representative of the Victorian population but may reflect students whom are most-likely to be at risk.

\section{CONCLUSION}

Contrary to previous findings, the during-school period constituted the greatest accumulation of MVPA for Grade 4 and Grade 6 children in the current sample. These findings highlight that among disadvantaged children, the school environment is a priority setting for interventions to promote PA at the expense of ST, especially among girls.

\section{Author affiliations}

${ }^{1}$ World Health Organization's Collaborating Centre for Obesity Prevention, Deakin Population Health, Deakin University, Geelong, Victoria, Australia 
${ }^{2}$ Nuffield Department of Population Health, British Heart Foundation Centre on Population Approaches for Non-Communicable Disease Prevention, University of Oxford, Oxford, Oxfordshire, UK

${ }^{3}$ School of Health and Social Development, Deakin University, Geelong, Victoria, Australia

Acknowledgements We would like to acknowledge Mr Aiden Doherty in offering his advice and assistance conducting the accelerometry management and analysis. The authors acknowledge the support and guidance from Professor Boyd Swinburn. They also acknowledge the support from the Victorian Department of Health and Human Services and the Victorian Department of Education and Training.

Contributors CS, LM and SA are all members of the executive committee overseeing the design, implementation and evaluation of the present study. $\mathrm{CS}, \mathrm{KT}, \mathrm{MM}$ and $\mathrm{JH}$ were responsible for the collection, entry and cleaning of the data with Foster providing critical data management and analytic expertise of the accelerometry data. CS led the development of the manuscript and all authors were involved in refining the paper and had final approval of the submitted and published versions.

Funding SA is supported by funding from an Australian National Health and Medical Research Council/Australian National Heart Foundation Career Development Fellowship (APP1045836). CS, MM, JH, LM and SA are researchers within an NHMRC Centre for Research Excellence in Obesity Policy and Food Systems (APP1041020). SA is supported by US National Institutes of Health grant titled Systems Science to Guide Whole-of-Community Childhood Obesity Interventions (1R01HL115485-01A1). LM is supported by an Alfred Deakin Early Career Research Fellowship. CF is funded by the British Heart Foundation.

Competing interests None declared.

Patient consent Obtained.

Ethics approval Prior to starting this study, ethical approvals from the Victorian Department of Education and Training (2013 002013), the Catholic Archdiocese of Melbourne, Sandhurst, Ballarat and Sale and Deakin University's Human Research Ethics Committee (2013_095) were sought and granted.

Provenance and peer review Not commissioned; externally peer reviewed.

Data sharing statement No additional data are available.

Open Access This is an Open Access article distributed in accordance with the Creative Commons Attribution Non Commercial (CC BY-NC 4.0) license, which permits others to distribute, remix, adapt, build upon this work noncommercially, and license their derivative works on different terms, provided the original work is properly cited and the use is non-commercial. See: http:// creativecommons.org/licenses/by-nc/4.0/

\section{REFERENCES}

1. Janssen I, Leblanc AG Systematic review of the health benefits of physical activity and fitness in school-aged children and youth. Int J Behav Nutr Phys Act 2010;7:40.

2. Strong WB, Malina RM, Blimkie CJ, et al. Evidence based physical activity for school-age youth. J Pediatr 2005;146:732-7.

3. Biddle SJ, Asare M. Physical activity and mental health in children and adolescents: a review of reviews. $\mathrm{Br} J$ Sports Med 2011;45:886-95.

4. Australian Bureau of Statistics. Australian health survey: physical activity, 2011-12. Canberra, Australia: Australian Bureau of Statistics, 2013.

5. Commonwealth Department of Health and Ageing. Physical activity recommendations for 5-12-year-olds. Canberra, ACT: Commonwealth Department of Health and Ageing, 2004.

6. Tremblay MS, LeBlanc AG, Kho ME, et al. Systematic review of sedentary behaviour and health indicators in school-aged children and youth. Int J Behav Nutr Phys Act 2011;8:98.

7. Uijtdewilligen L, Nauta J, Singh AS, et al. Determinants of physical activity and sedentary behaviour in young people: a review and quality synthesis of prospective studies. $\mathrm{Br} J$ Sports Med 2011;45:896-905.
8. Van Der Horst K, Paw MJ, Twisk JW, et al. A brief review on correlates of physical activity and sedentariness in youth. Med Sci Sports Exerc 2007;39:1241-50.

9. Han JC, Lawlor DA, Kimm SY. Childhood obesity. Lancet 2010;375:1737-48.

10. Dobbins M, Husson H, DeCorby K, et al. School-based physical activity programs for promoting physical activity and fitness in children and adolescents aged 6 to 18. Cochrane Database Syst Rev 2013;(2):CD007651.

11. Kriemler S, Meyer U, Martin E, et al. Effect of school-based interventions on physical activity and fitness in children and adolescents: a review of reviews and systematic update. $\mathrm{Br} J$ Sports Med 2011;45:923-30.

12. Biddle SJ, Petrolini I, Pearson N. Interventions designed to reduce sedentary behaviours in young people: a review of reviews. Br J Sports Med 2014;48:182-6.

13. Marsh S, Foley LS, Wilks DC, et al. Family-based interventions for reducing sedentary time in youth: a systematic review of randomized controlled trials. Obes Rev 2014;15:117-33.

14. Institute of Medicine. Accelerating progress in obesity prevention: solving the weight of the nation. Washington DC, 2012

15. Macinko JA, Starfield B. Annotated bibliography on equity in health, 1980-2001. Int J Equity Health 2002;1:1.

16. Atkin AJ, Gorely T, Biddle SJ, et al. Interventions to promote physical activity in young people conducted in the hours immediately after school: a systematic review. Int J Behav Med 2011;18:176-87.

17. van Stralen MM, Yildirim M, Wulp A, et al. Measured sedentary time and physical activity during the school day of European 10- to 12-year-old children: the ENERGY project. J Sci Med Sport 2014;17:201-6.

18. Nettlefold L, McKay HA, Warburton DE, et al. The challenge of low physical activity during the school day: at recess, lunch and in physical education. Br J Sports Med 2011:45:813-19.

19. Australian Bureau of Statistics. Census of population and housing: socio-economic indexes for areas (SEIFA), Australia, 2011. Canberra: Commonwealth of Australia, 2013.

20. Strugnell C, Millar L, Churchill A, et al. Healthy together Victoria and childhood obesity-a methodology for measuring changes in childhood obesity in response to a community-based, whole of system cluster randomized control trial. Arch Public Health 2016;74:16.

21. Card A, Manske S, Mammen G, et al. Core indicators and measures of youth health physical activity \& sedentary behaviour module: indicators and questions to use with youth respondents and/or school setting assessment. Newfoundland, Canada: Memorial University of Newfoundland, 2012.

22. Wong SL, Leatherdale ST, Manske SR. Reliability and validity of a school-based physical activity questionnaire. Med Sci Sports Exerc 2006;38:1593-600.

23. Parletta N, Cooper P, Petkov J, et al. Effects of fish oil supplementation on learning and behaviour of children from Australian Indigenous remote community schools: a randomised control trial. Prostaglandins Leukot Essent Fatty Acids 2013;89:71-9.

24. Varni JW, Limbers CA, Burwinkle TM. How young can children reliably and validly self-report their health-related quality of life? an analysis of 8,591 children across age subgroups with the PedsQL 4.0 Generic Core Scales. Health Qual Life Outcomes 2007;5:1.

25. Dental Health Services Victoria. Culturally and linguistically diverse communities-resource kit. Melbourne, Australia, 2010:39.

26. de Onis M, Onyango AW, Borghi E, et al. Development of a WHO growth reference for school-aged children and adolescents. Bull World Health Organ 2007;85:660-7.

27. Robusto KM, Trost SG. Comparison of three generations of ActiGraph activity monitors in children and adolescents. J Sports Sci 2012;30:1429-35.

28. Troiano RP, Berrigan D, Dodd KW, et al. Physical activity in the United States measured by accelerometer. Med Sci Sports Exerc 2008;40:181-8.

29. Rich C, Geraci M, Griffiths L, et al. Quality control methods in accelerometer data processing: defining minimum wear time. PLOS ONE 2013;8:e67206.

30. ActiGraph. ActiLife 6 user's manual. Pensacola, FL: ActiGraph, 2012:89.

31. Dollman J, Okely AD, Hardy L, et al. A hitchhiker's guide to assessing young people's physical activity: deciding what method to use. J Sci Med Sport 2009;12:518-25.

32. Romanzini M, Petroski EL, Ohara D, et al. Calibration of ActiGraph GT3X, Actical and RT3 accelerometers in adolescents. Eur J Sport Sci 2014;14:91-9. 
33. Butte NF, Ekelund U, Westerterp KR. Assessing physical activity using wearable monitors: measures of physical activity. Med Sci Sports Exerc 2012;44(Suppl 1):S5-12.

34. Arundell L, Salmon J, Veitch J, et al. Standardising the 'after-school' period for children's physical activity and sedentary behaviour. Health Promot J Austr 2013;24:65-7.

35. Commonwealth Department of Health. Australia's physical activity and sedentary behaviour guidelines for children (5-12 years). Canberra, 2014.

36. Olds T, Ridley K, Wake M, et al. How should activity guidelines for young people be operationalised? Int J Behav Nutr Phys Act 2007;4:43-9.

37. Cohen J. Statistical power analysis for the behavioural sciences. Hillsdale, NJ: Erlbaum, 1988.

38. Sallis JF, Prochaska JJ, Taylor WC. A review of correlates of physical activity of children and adolescents. Med Sci Sports Exerc 2000;32:963-75.

39. Salmon J, Tremblay MS, Marshall SJ, et al. Health risks, correlates, and interventions to reduce sedentary behavior in young people. Am J Prev Med 2011;41:197-206.
40. Payne S, Townsend N, Foster C. The physical activity profile of active children in England. Int $J$ Behav Nutr Phys Act 2013;10:136.

41. Tudor-Locke C, Lee SM, Morgan CF, et al. Children's pedometer-determined physical activity during the segmented school day. Med Sci Sports Exerc 2006;38:1732-8.

42. Stanley RM, Boshoff K, Dollman J. A qualitative exploration of the 'critical window': factors affecting Australian children's after-school physical activity. J Phys Act Health 2013;10:33-41.

43. Masse LC, Fuemmeler BF, Anderson CB, et al. Accelerometer data reduction: a comparison of four reduction algorithms on select outcome variables. Med Sci Sports Exerc 2005;37(Suppl 11): S544-54.

44. Freedson P, Pober D, Janz KF. Calibration of accelerometer output for children. Med Sci Sports Exerc 2005;37(Suppl 11): S523-30.

45. Harrell JS, McMurray RG, Baggett CD, et al. Energy costs of physical activities in children and adolescents. Med Sci Sports Exerc 2005;37:329-36. 